\title{
CORPOS REBELDES: SylVIA Plath E $A$ REDOMA DE VIDRO
}

Indocile Bodies: Sylvia Plath and The Bell Jar

\begin{abstract}
'Neurotic, ha!' I let out a scornful laugh. 'If neurotic is wanting two mutually exclusive things at one and the same time, then I'm neurotic as hell. I'll be flying back and forth from one mutually exclusive thing and another for the rest of my days.'
\end{abstract}

Sylvia Plath, em The Bell Jar

\section{Davi Ferreira de Pinho*}

\section{Sylvia Plath E A REDOMA DE VIDRO}

Em 1963, um livro chamado The Bell Jar, ou A Redoma de Vidro em português, era publicado. Uma nova romancista nascia, e seu nome assoalhava o paradoxo de um passado opressivamente puritano e uma história subversivamente irônica: seu nome era Victoria, como a rainha.

Victoria Lucas, descobriríamos depois, se tratava do pseudônimo escolhido por Sylvia Plath para esta narrativa controversa. A história de uma jovem mulher, Esther, que se sente perseguida por uma redoma de vidro que flutua sobre sua cabeça, moldando-a, prendendo-a à tradição da feminilidade; situando-a como o "Anjo do Lar" que Virginia Woolf matara havia vinte e dois anos em seu ensaio "Professions for Women" (2007).

Caroline King Barnard (1978) explicita que Plath pode ter usado um pseudônimo para resguardar sua vida pessoal, que teria servido de base para seu livro. Assim, Barnard classifica o livro como "um romance confessional", pois a maioria das situações e personagens tem paralelos reais na biografia de Plath, que estava passando por um período turbulento e queria revisitar sua juventude para enfim conectar conhecimento à

UERJ 
experiência, o passado ao presente, o desejo à realidade.

Tal processo levou Plath a escrever quarenta e três poemas, o que viria a ser Ariel, sua coletânea de maior sucesso; a concluir seu único romance, The Bell Jar; e a se suicidar - tudo ao longo do ano de 1963.

Se a vida de Sylvia Plath de fato inspirou sua arte - uma característica inegável desde a publicação completa de seus diários - não será peça fundamental em nossa leitura de The Bell Jar. O que deveremos discutir, no entanto, é como Sylvia Plath recusa o vitorianismo ainda presente na formação da identidade feminina moderna. Como esta autora, que se nomeia Victoria, cria uma personagem para subverter o "Anjo do Lar" vitoriano, fazendo nascer seu alter-ego, o que chamo de Demônio do Lar: Esther representa o declínio da mulher rumo à neurose. Não a neurose apontada pelo Outro, mas a neurose que lhe permite ser, falar, e agir; a loucura iluminadora - a apropriação do corpo abjeto como um caminho rumo à subjetivação.

\section{O DESEJO DE INFRAÇÃo: O ANJo E A FEMME FATALE}

I turned upon her and caught her by the throat. I did my best to kill her. My excuse, if I were to be had up in a court of law, would be that I acted in self-defense. Had I not killed her she would have killed me.

Virginia Woolf, em "Professions for Women"

Em The Bell Jar, percebemos já nas primeiras páginas uma querela interna que impede a subjetivação de Esther Greenwood: a personagem está presa entre os papéis de "Anjo do Lar" e de femme fatale.

Virginia Woolf já havia apontado a necessidade de aniquilação do ideal de feminilidade do Anjo do lar - ideal este herdado da Era Vitoriana. 0 assassinato do Anjo tornara-se então imperioso para o nascimento da escritora moderna. Woolf (2007) diz que seu eu e este eu idealizado não poderiam habitar o mesmo corpo; a questão era matar ou ser morta.

No entanto, Esther ainda se vê atormentada por tal ideal vitoriano. Ele permeia The Bell Jar na figura de personagens como Mrs. Greenwood, a mãe de Esther, Mrs. Willard, e principalmente Betsy - sua colega de bolsa estudantil que tenta resgatá-la de más influências. Estas personagens incorporam a homogeneidade do Anjo. Todavia, tais Anjos não estão presos ao ambiente familiar como no século dezenove. Elas viajam, estudam, e até trabalham - a periferia parece não mais existir no romance. Teria o ideal morrido?

Como apontado por Michel Foucault (1984), o poder trabalha através de concessões para regulamentar a transgressão. Assim, o poder sempre 
lucra com novas regras criadas para tais infrações. Esta "mecânica do poder", nome que o filósofo dá a tal mecanismo, disciplina nossos corpos, transformando-os em objetos rentáveis para o Estado, estando sempre sob medidas disciplinares. Deste modo, corpos dóceis são formados, e o que fora uma infração, ou transgressão - como mulheres fora da esfera do lar é legitimado.

Portanto, não nos surpreende que Esther seja incentivada por sua mãe a aprender taquigrafia. Mrs. Greenwood deixa claro que para Esther entrar no mercado de trabalho não poderá ser em base de igualdade com os homens; ela precisa ser uma boa secretária, não uma boa poeta. Esther percebe o mecanismo de castração social que the permite trabalhar, mas sempre como o segundo sexo subjugado à superioridade masculina.

$\mathrm{Na}$ academia, Esther também percebe que os novos Anjos podem, sim, estudar, mas a moda se torna mais um mecanismo de castração usado pelo poder. As universidades incentivam inclusive o uso de cadernos que combinem com seus vestidos. A personagem intui que se pode, sim, frequentar uma boa universidade, desde que tenham as roupas certas, como suas colegas de classe (PLATH, 1999).

A virgindade é ainda um forte predicado deste Anjo. Esther deseja liberdade sexual, ou controle sobre sua própria vida sexual. Entretanto, os panfletos de sua mãe estão sempre a lembrando de seu dever: ser uma noiva pura.

Foucault (1984) descreve o poder como sedutor. Ele gera um desejo de reprodução do discurso dos vencedores, dos colonizadores. É tal desejo de reprodução que mantém Esther cativa na companhia desses Anjos. Ela se vê atraída por esta perfeição, padronização, e superioridade de status.

No entanto, apesar de encontrar-se no papel de Anjo, quão fácil a reprodução de tal discurso para meninas de sua classe social, Esther confessa cedo no romance sua identificação com outra personagem. Esta representa nosso segundo papel em sua disputa interna: Doreen, a femme fatale.

Doreen representa o arquétipo de infratora. Ela não cumpre prazos, tem uma vida sexual ativa e está sempre ultrajando Betsy, chamando-a de "Pollyana Cowgirl", como se soubesse da batalha interna de Esther e quisesse denegrir sua oponente. Esther se identifica mormente com o papel erótico da femme fatale, precisamente por causa da sujeição da mulher virgem ao homem experiente que o casamento representava:

That's one of the reasons I never wanted to get married. The last thing I wanted was infinite security and to be the place an arrow shoots off from. I wanted change and excitement and to shoot off in all directions myself, like the coloured arrows from a Fourth of July rocket (PLATH, 1999, p. 88). 
Sabendo de sua inabilidade de transformar-se no Outro inexperiente subjugado à superioridade do homem desbravador, Esther traça uma vida de infração gratificante para si: "I decided I would put off the novel until I had gone to Europe and had a lover, and that I would never learn a word of shorthand. If I never learned shorthand I would never have to use it" (PLATH, 1999, p. 129).

Por mais incisiva que sua nova resolução seja, Esther ainda se vê presa por sua criação, e estagnada entre ambos os papéis de Anjo e femme fatale:

[...] I wondered why I couldn't go the whole way doing what I should anymore. This made me feel sad and tired. Then I wondered why I couldn't go the whole way doing what I shouldn't, the way Doreen did, and this made me even sadder and more tired (PLATH, 1999, p. 31).

Esther então sente o peso de uma enorme redoma de vidro que flutua sobre sua cabeça, impedindo-a de quebrar a tradição e viver a infração tão desejada. Ela chega à conclusão de que, independentemente de onde se encontre, ela estaria sempre presa nesta redoma, cozinhando em seu próprio ar rarefeito, como Plath metaforiza (1999, p. 195).

Podemos facilmente traçar um paralelo aqui entre esta redoma de vidro e o que Foucault chama de certa alma governando nossos corpos sociais. Esta alma constitui-se de regras milenares que estão sempre se disfarçando para moldar-nos à igualdade e complacência. Enquanto o corpo revolta-se, a alma enquadra-o em sua função social. Para Foucault, o corpo é prisioneiro da alma:

[...] the body is also directly involved in a political field; power relations have an immediate hold upon it; they invest it, mark it, train it, torture it, force it to carry out tasks, to perform ceremonies, to emit signs. This political investment of the body is bound up, in accordance with complex reciprocal relations, with its economic use; it is largely as a force of production that the body is invested with relations of power and domination; [...]

[The soul] is born rather out of methods of punishment, supervision, and constraint. This real, noncorporal soul is not a substance; it is the element in which are articulated the effects of a certain type of knowledge, the machinery by which the power relations give rise to a possible corpus of knowledge, and knowledge extends and reinforces the effects of this power. [...] The soul is the effect and instrument of a political anatomy; the soul is the prison of the body (FOUCAULT, 1984, p. 173, 177). 
Esta alma estava tão enraizada, seu corpo tão envolto, que Esther não poderia escolher o papel de femme fatale, mesmo que ali visse seu real ser. Seu corpo parara de revoltar-se, sua mente o fazia, mas seu corpo tornara-se dócil. Esta alma conseguira proteger sua existência ornamental, seu papel social, por fora; mas, em seu pensamento, a batalha ainda não havia acabado. E, por isso, ser o Anjo também era impraticável.

Uma noite, enfim, Esther começa a alimentar o vento com seu guarda-roupa, como ela mesma descreve (PLATH, 1999, p. 118). Tomada pelo sentimento de inadequação, ela volta para o hotel em Nova York e resolve matar o anjo, matar o seu Eu complacente, e assim ataca seu guardaroupa. A cada peça jogada pela janela ela tenta quebrar o vidro da redoma, libertar o corpo da alma. Aí então começa a jornada para fora do $\mathrm{Eu}$; o declínio à loucura escolhido deliberadamente. Aqui, a loucura é libertadora; ela vem da própria personagem. Ela aceita sua posição de neurótica para poder usar o discurso livre, independentemente das regras que regem $o$ discurso dos sãos. O objetivo? Matar o Anjo.

Mas como pode Esther matar tal ideal, ou quebrar a redoma, quando isto constitui sua própria alma?

\section{O CORPo Abjeto, ou o Poder da Morte}

To the person in the bell jar, blank and stopped as a dead baby, the world itself is the bad dream.

Sylvia Plath, em The Bell Jar

Esther Greenwood representa o Demônio do Lar em busca de uma nova identidade a partir do momento em que decide habitar o campo de batalha entre o Anjo do Lar e a femme fatale. Esta seria a única rota para fora desta redoma de vidro que mantém seu corpo em cativeiro.

Esther mostra uma incapacidade de situar-se, de desejar, de pertencer; ou até mesmo de recusar um padrão estabelecido. É exatamente esta falta de possibilidades no mundo vivenciado como um pesadelo que a leva ao espaço de alucinações do corpo abjeto de que nos fala Julia Kristeva:

Not me. Not that. But not nothing, either. A "something" that I do not recognize as a thing. A weight of meaninglessness, about which there is nothing insignificant, and which crushes me. On the edge of nonexistence and hallucination, of a reality that, if I acknowledge it, annihilates me. There, abject and abjection are my safeguards. The primers of my culture (1982, p. 2). 
Esta leitura da abjeção implica uma fusão sociopolítica da teoria do poder de Foucault e das subdivisões do self de Freud, que Kristeva explora. $O$ abjeto transforma-se em certo corpo incapaz de residir dentro das fronteiras limitadoras de sua alma; certo ego inábil de conformar-se com seu superego. o que acontece, então, com este corpo incapaz de passar do imaginário ao simbólico? Como este ser, definido não como sujeito nem objeto, penetrará a linguagem e alcançará integridade corporal?

Esther começa uma jornada fora de Nova York, e fora da universidade, em busca de tais respostas. Cada vez mais Esther abre mão de seus sonhos de escrever um romance, viajar e ter um amante, pois mesmo longe de tudo ainda sente a redoma flutuando sobre seu corpo.

Em uma tarde de desalento, Esther se entrega à água do mar e nada até não ter forças de retornar à praia. Em desespero por uma resposta, prestes a sucumbir, ela ouve seu coração batendo num ritmo elucidativo: "I am, I am, I am" (PLATH, 1999, p. 166).

Seu coração esclarece sua linha de ataque: ela era quando não era. Esther só encontrara seu sujeito quando à beira da morte. Tentando apreender a profundidade de tal descoberta, ela começa a experimentar a morte e estudar maneiras de matar o corpo para destruir a alma, já que os dois apresentavam-se interligados:

I crawled between the mattress and the padded bedstead and let the mattress fall across me like a tombstone. It felt dark and safe under there, but the mattress was not heavy enough. I needed about a ton more weight to make me sleep (PLATH, 1999, p. 130).

É então, no zênite de sua loucura, ou incapacidade de interpretar seu papel enquanto mulher numa sociedade patriarcal, que Esther arquiteta sua morte, mascarando tal desejo para não ser internada antes de alcançar seu objetivo. No entanto, sua alma incorporada não permite que seu corpo sucumba e ela descobre mecanismos de resistência, paralelos aos quais Foucault nos fala nas relações de poder, em seu próprio corpo:

[...] I saw that my body had all sorts of little tricks, such as making my hands go limp at the crucial second, which would save it, time and again, whereas if I had the whole say, I would be dead in a flash (PLATH, 1999, p. 167).

Como é claro na citação acima, Esther dissocia seu self de seu corpo. Ela não é mais a matéria que ocupa aquele espaço. Ela só será livre quando seu Eu estiver livre desta alma enraizada no corpo que mostra resistência. A morte do corpo governado por esta alma torna-se central para 
o processo de reabilitação de Esther. Morte transforma-se em vida - poderia ela chegar a outra conclusão?

\section{Denegando o CadÁver: O Corpo Deformado}

The first - killing the Angel in the House - I think I solved. She died. But the second, telling the truth about my experiences as a body, I do not think I solved. I doubt that any woman has ever solved ityet.

Virginia Woolf, em "Professions for Women"

Esther encontra-se igualmente incapaz de vivenciar o mundo que deseja através de seu corpo dócil ou de matá-lo, já que ele resiste. É na esperança de vencer a batalha contra seu próprio corpo que Esther ingere um frasco de calmantes e enterra-se em seu próprio porão.

Mesmo à sombra do ser, no hiato entre seu Eu e o mundo, sua alma incorporada ainda acha maneiras de mostrar sua superioridade. Ali, morta por uma semana, sua alma zomba de seu corpo através de uma voz que diz "você casará com um homem cego", já que ela estava ali, sem visão, mas não morta; tendo assim de cumprir seu papel social. Após uma semana enterrada, sua alma vence a batalha temporariamente: a mãe de Esther a encontra e decide interná-la.

Esther ainda deseja a morte de seu corpo dócil, mas é seu próprio corpo deformado pela morte que produz seu primeiro passo rumo à subjetivação, através do que Kristeva $(1982$, p. 6) define como a base da existência: o medo.

Esther teme seu reflexo no espelho. Ela não consegue enxergar-se na figura careca, retalhada de pontos e inchada que vê refletida. Kristeva (1982) elucida que é o cadáver, e não a morte, que deve ser denegado para que haja um sujeito. Então, o medo do corpo morto torna-se a força motora que propele os seres humanos rumo à subjetivação.

Até então, Esther havia baseado sua existência na recusa da vida, a morte sendo sua jouissance. Ao confrontar-se com seu próprio cadáver no espelho, ela desloca seu Eu, como Kristeva aclara:

A wound with blood and pus, or the sickly, acrid smell of sweat, of decay, does not signify death - a flat encephalograph for instance - I would understand, react, or accept. No, as in true theatre, without makeup or masks, refuse and corpses show me what I permanently thrust aside in order to live. These body fluids, this defilement, this shit are what life withstands, hardly and with difficulty, on the part of death. There, I am at the border of my 
condition as a living being. My body extricates itself, as being alive, from that border. Such wastes drop so that I might live, until, from loss to loss, nothing remains in me and my entire body falls beyond the limit - cadere, cadaver. If dung signifies the other side of the border, the place where I am not and which permits me to be, the corpse, the most sickening of wastes, is a border that has encroached upon everything. It is no longer I who expel, "I" is expelled (KRISTEVA, 1982, p. 3).

O cadáver é a fronteira da existência, o lugar onde o Eu para de ser e que permite que este Eu seja o que desprezo: esterco, excremento, sujeira. Então, Kristeva conclui que não é o Eu que expele, mas é expelido. o cadáver invade o mundo do self, e é aí que Esther percebe, inconscientemente, que o ser e o náo ser não podem coexistir. O não ser transformaria seus pensamentos em nada; a desmaterialização de seu corpo não mataria a alma.

A partir do momento em que Esther entra no sanatório, após seu quase suicídio, sua meta de matar o corpo prisioneiro desta alma começa a mudar dentro de si mesma. Ela torna-se uma observadora de suas companheiras de confinamento, inconscientemente traçando os passos que a levariam a tal assassinato sem confrontar seu próprio cadáver outra vez.

o que matar é claro; a única questão é como.

\section{Demanda De Morte: O Duplo de Esther}

It was as if what I wanted to kill wasn't in that skin or the thin blue pulse that jumped under my thumb, but somewhere else, deeper, more secret, and a whole lot harder to get at.

Sylvia Plath, em The Bell Jar

No dia em que Esther é promovida para uma casa melhor dentro do sanatório onde está internada, a heroína de Plath surpreende-se ao encontrar Joan, uma "antiga amiga", como a chama, hospedada no quarto ao lado.

Quando a heroína vê Joan, ela diz que sua amiga estava esbaforida, como se tivesse corrido uma longa distância e só agora encontrado um ponto fixo. Tal comentário é deslocado no texto, já que somos informados que Joan está sentada há algum tempo apenas esperando por Esther (cf. PLATH, 1999, p. 204). A corrida, aqui, pode ser lida como a corrida rumo à materialização atendendo à demanda de morte de Esther: Joan levanta-se como o duplo de Esther para cumprir sua missão de morte.

Joan, uma personagem concebida na azáfama da mente de Esther, apresenta-se como uma cópia exata dela. Elas dividem o mesmo passado, 
até mesmo o romance com Buddy Willard. Em suma, podemos discutir que Joan representa a alma incorporada de Esther. Ela representa o conjunto de regras que a encurralava dentro da redoma de vidro que, agora cortada de seu corpo, possibilita um distanciamento libertador. Duplicando-se, Esther consegue enfim entender e desenvolver seu próprio Eu; agora conseguirá optar por um papel.

Ela observa a jornada bem-sucedida de Joan, sempre galgando posições melhores dentro do sanatório por manter uma boa relação com as pacientes mais ricas, as enfermeiras; enfim, por seguir as regras normativas da sociedade, assim como Esther o fazia quando ainda presa nesta alma regulatória.

Quando Esther está na última casa antes de ser considerada sã outra vez, Belsize, ela se vê de novo sob a fiscalização de Joan. Agora sua alma é material; Esther enxerga os mecanismos de poder de que Foucault nos fala. Sendo assim, ela entende a mecânica do medo que transfere sua alma opressiva para o corpo de Joan:

Joan had walk privileges. Joan had shopping privileges. Joan had town privileges. I gathered all my news of Joan into a little, bitter heap, though I received it with surface gladness. Joan was the beaming double of my old best self, specially designed to follow and torment me (PLATH, 1999, p. 216).

Esther percebe que a função de Joan era precisamente atormentála, persegui-la, oprimi-la em direção à redoma de vidro mais uma vez. Esther então tenta entender a cátedra de Joan em sua vida:

\begin{abstract}
Her thoughts were not my thoughts, nor her feelings my feelings, but we were close enough so that her thoughts and feelings seemed a wry, black image of my own. Sometimes I wondered if I had made Joan up. Other times I wondered if she would continue to pop in at every crisis of my life to remind me of what I had been, and what I had been through, and carry on her own separate but similar crisis under my nose (PLATH, 1999, p. 231).
\end{abstract}

Joan representa o passado de Esther; a alma foucaultiana incorporada; a redoma de vidro; o Anjo. Ela era exatamente o que Esther tentara matar ao tentar o suicídio. Agora, no espaço de alucinações habitado pelo corpo abjeto, Esther conseguira achar uma maneira de matar seu self e ainda viver: há afinal rachaduras na redoma de vidro. 


\section{Quebrando a Redoma: O Corpo Vive, A Alma morre}

It is far harder to kill a phantom than a reality. She was always creeping back when I thought I had dispatched her.

Virginia Woolf, em "Professions for Women"

Pouco tempo após a ascensão de Esther para a última casa antes de receber alta, Joan anuncia sua cura e deixa o sanatório. É neste período, em que os olhos de Joan não estão a poli-la, que Esther começa sua transgressão. Como sua alma opressora já não habita seu corpo, Esther tenta matar a primeira característica do Anjo: sua virgindade.

Agora que seu Eu dócil fora projetado para fora de si, Esther sente que tal passo poderá tirá-la do espaço de alucinações do corpo abjeto e situá-la em uma posição de sujeito. Portanto, após achar Irwin, um professor universitário que preenchia todos seus pré-requisitos para um parceiro sexual, Esther entrega-se à tradição da mulher transgressora.

Após o ato, Esther começa a delinear as fronteiras de seu ser, aniquilando a fluidez das margens do corpo abjeto. Ela localiza-se no mundo: "I smiled into the dark. I felt part of a great tradition" (PLATH, 1999, p. 242).

Apesar do prazer de pertencimento, Esther tem uma hemorragia logo após a relação sexual. É como se, mais uma vez, sua alma punisse seu corpo. Então, Esther demanda que Irwin a deixe na casa de Joan: corpo e alma estão reunidos, mais uma vez.

Após estancada a hemorragia, Joan muda-se para o sanatório com Esther como antes. Joan percebe a iminência de um corpo livre, e tenta ganhar controle sobre Esther mais uma vez. No entanto, Esther se juntara a um grupo: parte de uma tradição, ela não é mais um corpo deslocado, sem fronteiras, disciplinado e dócil.

Sob a luz de seu novo $\mathrm{Eu}$, um Eu que pertence, Esther termina com o maior impedimento em sua jornada rumo ao ser: Joan. Com o suicídio de seu duplo, a heroína de Sylvia Plath enfim quebra a redoma de vidro e extrai o corpo da alma: através de Joan, Esther mata seu próprio corpo dócil.

É então, no enterro de seu corpo domesticado, representado por Joan, que Esther ouve mais uma vez o ritmo familiar de seu coração, o mesmo que mostrara uma vez o caminho rumo à liberdade fora da redoma de vidro: "during the simple funeral service I wondered what I thought I was burying. [...] I took a deep breath and listened to the old brag of my own heart. I am, I am, I am" (PLATH, 1999, p. 256). 
Após a morte de seu duplo, Esther tem alta, seguindo rumo ao mundo como um bebê. Pontos de interrogação à frente; uma nova identidade a se formar, liberta da alma que a aprisionara.

\section{Elaine, Esther, Sylvia: Corpos Rebeldes}

What I fear most, I think, is the death of the imagination. [...] If I sit still and don't do anything, the world goes on beating like a slack drum, without meaning. We must be moving, working, making dreams to run toward; the poverty of life without dreams is too horrible to imagine.

Sylvia Plath, em The Unabridged Journals of Sylvia Plath

Em The Bell Jar, antes de entregar-se à neurose e ao espaço de alucinações do corpo abjeto como um atalho rumo à subjetivação, a personagem de Sylvia Plath, Esther, tenta refletir o peso do ideal do Anjo do Lar no papel. Ela pretende escrever um romance sobre Elaine: seis letras para representar as seis letras de seu próprio nome - Esther seria Elaine. E para Sylvia, haveria Esther: seis letras.

Esther só consegue matar um ideal opressor após presenciar a morte de seu próprio corpo dócil externalizado de si. Ela consegue reverter os mecanismos de poder entre alma e corpo dos quais nos fala Foucault, subvertendo assim o papel da mulher e apropriando-se de sua nova posição: aquela que tem a escolha de ser.

Seria impossível separar Plath de Esther: ambas fazem da criatividade, da morte do corpo e do discurso livre dos neuróticos seus atalhos rumo à subjetivação.

Sylvia, como sua predecessora Woolf, só conseguiu produzir Esthers; nenhuma Joan. Entretanto, viva está através de uma grande tradição. Ela é o corpo rebelde em luta constante com a alma; o Demônio do Lar; aquela que espostejou o corpo do Anjo, sacrificando o seu.

\section{RESUMO}

Sylvia Plath, em The Bell Jar, explicita a luta ainda presente no inconsciente da mulher moderna entre o anjo do lar e a femme fatale. O que pretendo discutir são os mecanismos que Plath utiliza para demonstrar a incompatibilidade de sua heroína com ambos os papéis de expressão feminina e sua consequente jornada rumo à abjeção de que Kristeva nos fala, passando pelo desejo da morte e a neurose.

Palavras-chave: estudos feministas; abjeção; morte. 


\begin{abstract}
In The Bell Jar, Sylvia Plath depicts the struggle between The Angel in The House and the femme fatale still present in the modern woman's unconsciousness. In this paper, I intend to discuss the mechanisms which Plath uses in order to portray her heroine's inability to perform either role, showing her subsequent journey into Kristeva's abjection, which involves neurosis and longing for death.

Keywords: feminist studies; abjection; death.
\end{abstract}

\title{
REFERÊNCIAS
}

BARNARD, Caroline King. Sylvia Plath. Boston: Twayne's United States Authors Series, 1978.

FOUCAULT, Michel. The history of sexuality - Volume One. New York: Vintage, 1970.

Microfísica do poder. São Paulo: Graal, 2005.

The body of the condemned. In: RABINOW, Paul. (Ed.). The Foucault Reader. Toronto: Penguin Books, 1984.

Docile bodies. In: RABINOW, Paul. (Ed.). The Foucault Reader. Toronto: Penguin Books, 1984.

KRISTEVA, Julia. Powers of horror; an essay on abjection. New York: Columbia University Press, 1982.

PLATH, Sylvia. The bell jar. London: Faber and Faber, 1999.

The unabridged journals of Sylvia Plath. New York: Anchor Books, 2000.

WOoLf, Virginia. Professions for women. In: GUBAR, Susan. (Ed.). The Norton anthology of literature by women. New York: W.W. Norton \& Company, 2007. v. 2.

Enviado em: 22/10/2009

Aceito em: 27/01/2010 